\title{
Preparation and Characterization of zirconia-core ceria -shell composites and its formation mechanism
}

\author{
Xilu Hou ${ }^{\mathrm{a}}$, Kehui Qiu ${ }^{\mathrm{b}}$, Min Zhang, Wenjian Tang, GongGong Lu, Xiqiang Yuan, Qianchen Liu \\ School of Chengdu University of technology, Chengdu 510069, China; \\ 15828293524@163.com, qkh2188@163.com
}

Keywords: zirconia-ceria, core-shell structure, chemical precipitation method, mechanism.

\begin{abstract}
In this work, a strategy was developed for the synthesis of nano-sized, zirconia-core ceria -shell composites directly via chemical precipitation method in mixed solvents. The as-synthesized $\mathrm{ZrO}_{2} @ \mathrm{CeO}_{2}$ composites were characterized by X-ray diffraction (XRD), zeta potential analysis, field emission scanning electron microscope (FESEM), energy dispersive spectrum (EDS) and transmission electron microscopy (TEM). The results indicated that the fabricated $\mathrm{ZrO}_{2} @ \mathrm{CeO}_{2}$ composites were irregular spheroids and were uniformly coated by cubic fluorite $\mathrm{CeO}_{2}$ nanoparticles. Based on the effects of $\mathrm{pH}$ value on coating performances, a possible formation mechanism of zirconia-ceria composite was deduced and summarized.
\end{abstract}

\section{Introduction}

Over last few years, the study on fabricating nanocoating or core-shell structure particles had been promoted rapidly, principally due to such composite particles possessed special structure and morphology, which would exhibit novel performances that were substantially different from those of the cores, thus making them attractive from both scientific and technological viewpoints.[1-3] With the fabrication, the applications of nanocoating or core-shell structure materials therewith fill our daily life nearly in every aspect, ranging from LCD materials, [4] fuel cells[5] and other civilian areas to stealth materials[6] in military.

As a vital sort of rare earth resources, nanocrystalline ceria is a multifunctional material with a wide range of applications in exhaust treatment,[7] UV absorber[8] and surface lapping and polishing materials.[9] However, with the exploitation and export of rare earth being limited, the international price shows a drastic rising trend. So, on the premise of the properties of product being guaranteed, the interest is spurred to reduce the mixed rare earth cerium as much as possible in above-mentioned fields. In this context, as a practical approach for minimizing Ce loading on nanomaterials, manufacturing core-shell composites have prompted an unprecedented interest in related fields.

Currently, the preparation of core-shell materials are mainly based on two feasible means. One is to make the cores treated with coupling agents (e.g., silane-coupling agents) so as to form chemical bonds between core and shell particles. Another way is making an appropriate treatment to cores with either using surfactants or adjusting $\mathrm{pH}$ value to enhance or reverse surface charge to form strong electrostatic attractions between the cores and the shells. Armini et al.[10] prepared PMMA-core ceria-shell composites by adjusting $\mathrm{pH}$ value and investigated their CMP behavior for $\mathrm{SiO}_{2}$ dielectric layers. Zheng et al.[11] fabricated Ag/C core-shell composite materials by chemical deposition, and the results indicated that the $\mathrm{pH}$ value and surfactants imposed significant influences on silver coating. In addition. All these experimental results indicated that core-shell composites resulted in reducing the coating-materials loading, but improving the functional performance in evidence.

In view of ceria and zirconia have a certain similarity in terms of physical, chemical and thermal stability[12], $\mathrm{ZrO}_{2}-\mathrm{CeO}_{2}$ nanocomposites can be used as a substitute in many ceria application fields. To the best of our knowledge, no report has been devoted to the preparation of zirconia-core ceria -shell composites by chemical precipitation method in stiu. Hence, we attempt to produce inorganic $\mathrm{CeO}_{2}$-coated $\mathrm{ZrO}_{2}$ composites. In this work, our studies are aimed at preparing zirconia-core ceria 
-shell composite by chemical precipitation method in stiu and summarizing its formation mechanism via turning the $\mathrm{pH}$ condition.

\section{Experimental}

\subsection{Materials.}

Zirconium dioxide was purchased from Aladdin Industrial Corporation (Shanghai, China). Hexamethylene tetramine (HMT) were obtained from Kelong Chemical Reagent Co. Ltd (Chengdu, China). Remaining chemical reagents, including cerium nitrate hexahydrate $\left(\mathrm{Ce}\left(\mathrm{NO}_{3}\right)_{3} \cdot 6 \mathrm{H}_{2} \mathrm{O}\right)$, sodium hydroxide $(\mathrm{NaOH})$ and absolute ethanol were of analytical grade and were purchased from Sinopharm Chemical Reagent Co. Ltd (Shanghai, China). All reagents were used without any further purification. Deionized water was used throughout the experiment.

\subsection{Synthesis of $\mathrm{ZrO}_{2} @ \mathrm{CeO}_{2}$ composite particles.}

Preparation of $\mathrm{ZrO}_{2}$ suspensions - $\mathrm{ZrO}_{2}$ powder was dispersed in absolute ethanol under magnetic stirring, and then added $2 \mathrm{M} \mathrm{NaOH}$ aqueous solutions. To get homogeneous suspension, the resulting mixture was treated by ultrasonic for $1 \mathrm{~h}$ under room temperature, and then preserved for further use in experiments.

Preparation of $\mathrm{ZrO}_{2} @ \mathrm{CeO}_{2}$ composites-In a typical process, a certain concentration of $\mathrm{Ce}\left(\mathrm{NO}_{3}\right)_{3} \cdot 6 \mathrm{H}_{2} \mathrm{O}$ solutions were added slowly into well dispersive $\mathrm{ZrO}_{2}$ suspension. By the mixture slowly heated to $75{ }^{\circ} \mathrm{C}$, excessive amounts of hexamethylenetetramine(HMT) as precipitant were added in drops into the mixture under continuously stirring. After the titration of HMT solutions, the mixture was deposited for $2 \mathrm{~h}$ under room temperature. Then the resulting precipitates were centrifuged and washed with deionized water and ethanol to remove any possible remnants. Final products were collected by drying overnight at $60{ }^{\circ} \mathrm{C}$ in air and calcination at $600{ }^{\circ} \mathrm{C}$ for $2 \mathrm{~h}$.

\subsection{Characterization.}

The XRD measurements of synthesized products were attained by a DX-2700 X-ray diffractometer (Fangyuan Ltd, China) using $\mathrm{Cu} \mathrm{K \alpha}$ radiation $(\lambda=0.154056 \mathrm{~nm})$. Zeta potential versus $\mathrm{pH}$ curves of samples was determined by using a ZetaPALS instrument(BIC, USA). Scanning electron microscope (SEM) micrographs were attained by Ultra 55 (carl zeiss SMT Pte Ltd, Germany). The morphology of the products was examined by using a Transmitting Electron Microscope (Libra 200FE, carl zeiss SMT Pte Ltd, Germany) with an acceleration of $10 \mathrm{kV}$.

\section{Results and discussion}

\subsection{The effect of $\mathrm{pH}$ value on coating performance.}

Electrostatic attractive interaction was acknowledged as a prime mechanism for the formation of core-shell structure materials. The surface charge characteristic of cores would reflect the electroadsorption rate or whether the electrostatic attractions will happen between cores and shell particles. Surface charge against $\mathrm{ZrO}_{2}$ cores is shown in Fig. 1. The electrophoretic mobility measurements gave a zeta potential of $10 \mathrm{mV}$ at neutral $\mathrm{pH}$. With $\mathrm{pH}$ value increasing, the potential of $\mathrm{ZrO}_{2}$ shown a decreasing trend and reached isoelectric point (IEP) at the $\mathrm{pH}$ value of 7.9.

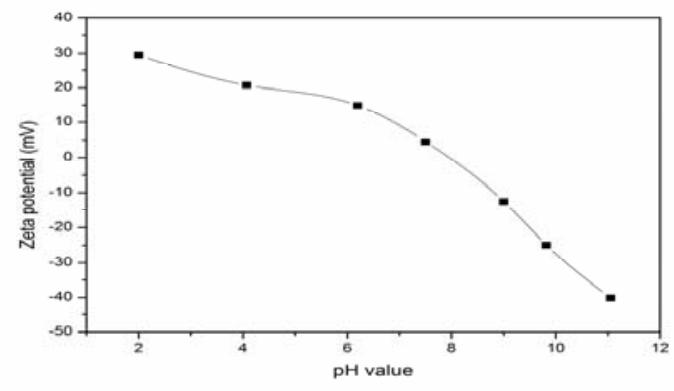

Fig. 1 Zeta potential of $\mathrm{ZrO}_{2}$ as a function of the $\mathrm{pH}$ values. 
The $\mathrm{pH}$ value of the $\mathrm{ZrO}_{2}$ suspensions was measured 6.5 and in this condition the $\mathrm{ZrO}_{2}$ particle carried positive charge, as shown in Fig. 1, which conflicted with electrostatic attractions of $\mathrm{ZrO}_{2}$ (core) and $\mathrm{Ce}^{3+}$ cations(shell). To exert strong electrostatic attractive behavior between $\mathrm{ZrO}_{2}$ cores and $\mathrm{Ce}^{3+}$ cations, it is feasible to change the surface charge of zirconia particles by adjusting $\mathrm{pH}$ value. The hydroxyl concentration of $\mathrm{Ce}(\mathrm{OH})_{3}$ precipitation generating was calculated using Eq.(1). The conversion of hydroxyl concentration and $\mathrm{pH}$ value was measured using Eq.(2) and Eq.(3).

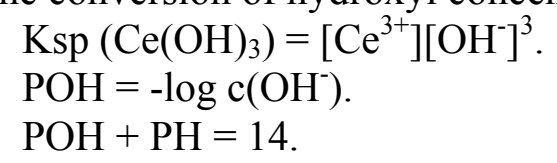

Here, Ksp is a constant of $1.5 \times 10^{-20}$ at $25^{\circ} \mathrm{C}$.[13]

Therefore, we turned the $\mathrm{pH}$ value of $\mathrm{ZrO} 2$ suspensions to 8.1 using $2 \mathrm{M}$ sodium hydroxide aqueous solution before the addition of HMT solution.

Fig. 2 shows the XRD patterns of $\mathrm{ZrO}_{2} @ \mathrm{CeO}_{2}$ composites. Compared with original zirconia particles (Fig. 2a), the spectrum of Fig. 2b-c revealed well-developed reflection of cubic fluorite-type structure ceria (JCPDS 34-0394). Furthermore, the diffraction peak at around 28.2 had broaden distinctly and the main diffraction peaks of zirconia remained but obviously weakened, which might attribute to the coating of the $\mathrm{CeO}_{2}$ particls around $\mathrm{ZrO}_{2}$ cores partly.[14]

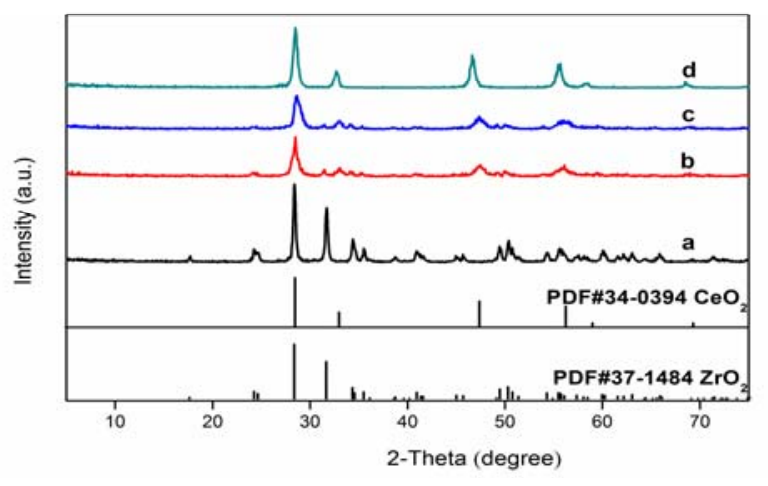

Fig. 2 XRD patterns of $\mathrm{ZrO}_{2}, \mathrm{CeO}_{2}$ and $\mathrm{ZrO}_{2} @ \mathrm{CeO}_{2}$ composites. (a) $\mathrm{ZrO}_{2}$, (b)

$\mathrm{ZrO}_{2} @ \mathrm{CeO}_{2}-\mathrm{NaOH}\left(\mathrm{ZrO}_{2}\right.$ suspensions with $\mathrm{NaOH}$ surface treatment), (c) $\mathrm{ZrO}_{2} @ \mathrm{CeO}_{2}\left(\mathrm{ZrO}_{2}\right.$ suspensions without any surface treatment), (d) $\mathrm{CeO}_{2}$.

Fig. 3 displays the zeta potential of $\mathrm{ZrO}_{2} @ \mathrm{CeO}_{2}-\mathrm{NaOH}$ composites. The IEP value of $\mathrm{CeO}_{2}$ and $\mathrm{ZrO}_{2}$ was around 6.8 and 7.9 respectively, while the IEP of $\mathrm{ZrO}_{2} @ \mathrm{CeO}_{2}-\mathrm{NaOH}$ composites was 7.1, which shown a significant shift toward pure $\mathrm{CeO}_{2}$. Herein, it suggested that the ceria-coated zirconia composite particles had been synthesized in some degree. As for the IEP of composites did not coincide with ceria absolutely, it might owe to the ceria shell was incomplete or the $\mathrm{ZrO}_{2}$ core still exerted effects on the zeta potential of the $\mathrm{CeO}_{2}$ particle comprising the shell.[15]

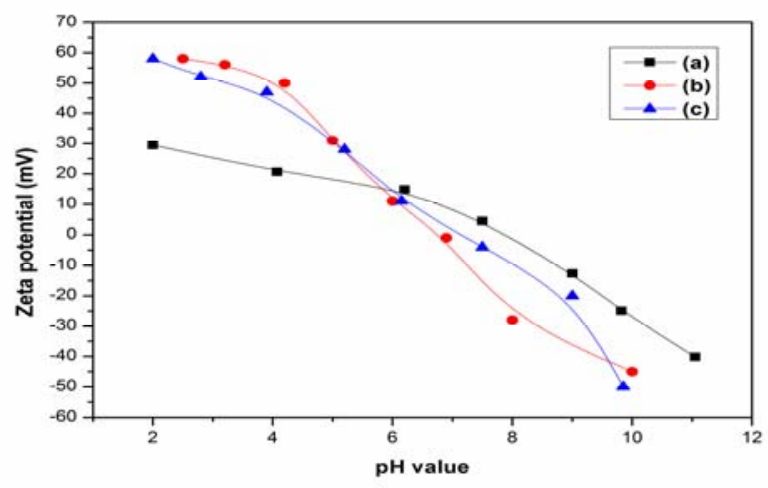

Fig. 3 Zeta potential as a function of the $\mathrm{pH}$ values: (a) $\mathrm{ZrO}_{2}$, (b) $\mathrm{CeO}_{2}$ and (c) $\mathrm{ZrO}_{2} @ \mathrm{CeO}_{2}-\mathrm{NaOH}$ composites 
Fig. 4 shows the SEM and EDS results of $\mathrm{ZrO}_{2} @ \mathrm{CeO}_{2}-\mathrm{NaOH}$ and $\mathrm{ZrO}_{2} @ \mathrm{CeO}_{2}$ composites. Compared with $\mathrm{ZrO}_{2}$ particles (Fig. 4a), the significant change was the composite particles presented rough surfaces and on closer examination the size of composites was really increased. Besides, the EDS results both confirmed that there was a significant amount of $\mathrm{Ce}$ and $\mathrm{O}$ on the surface of zirconia, which was in accordance with XRD and Zeta analysis results. The data in Table 1 revealed that the amount of $\mathrm{Ce}$ element on the surface of $\mathrm{ZrO}_{2} @ \mathrm{CeO}_{2}$ composites was lower than that of $\mathrm{ZrO}_{2} @ \mathrm{CeO}_{2}-\mathrm{NaOH}$ composites.
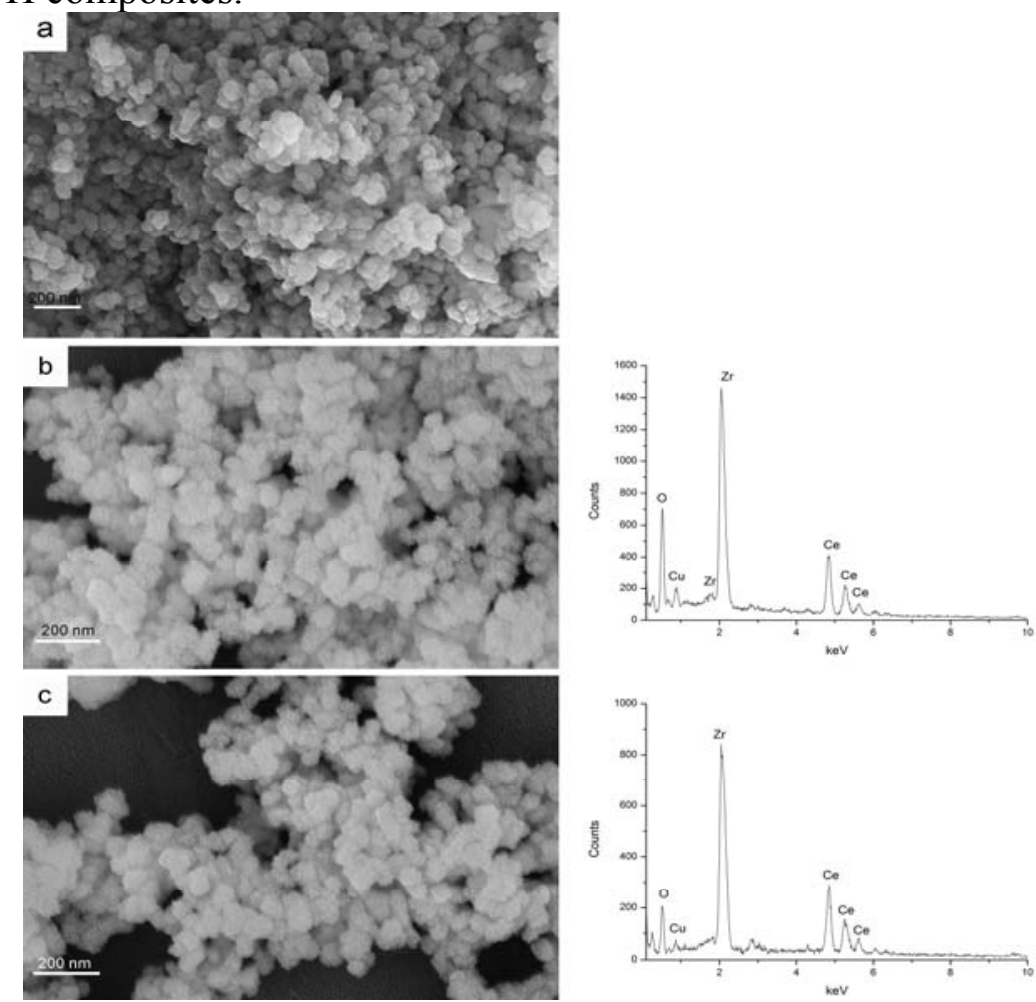

Fig. 4 FESEM images (left) and EDS spectra (right) of composites. (a) $\mathrm{ZrO}_{2}$, (b) $\mathrm{ZrO}_{2} @ \mathrm{CeO}_{2}-\mathrm{NaOH}$ and (c) $\mathrm{ZrO}_{2} @ \mathrm{CeO}_{2}$.

Table 1 Element compositions of $\mathrm{ZrO}_{2} @ \mathrm{CeO}_{2}$ composites and $\mathrm{ZrO}_{2} @ \mathrm{CeO}_{2}-\mathrm{NaOH}$ composites.

\begin{tabular}{ccc}
\hline Elements & $\begin{array}{r}\mathrm{ZrO}_{2} @ \mathrm{CeO}_{2}-\mathrm{NaOH} \text { composites } \\
(\mathrm{wt} \%)\end{array}$ & $\begin{array}{c}\mathrm{ZrO}_{2} @ \mathrm{CeO}_{2} \text { composites } \\
(\mathrm{wt} \%)\end{array}$ \\
\hline $\mathrm{O}$ & 30.41 & 35.06 \\
$\mathrm{Cu}$ & 2.01 & 1.69 \\
$\mathrm{Ce}$ & 23.71 & 15.08 \\
$\mathrm{Zr}$ & 43.87 & 48.17 \\
\hline
\end{tabular}

TEM provides an intuitively effective tool to observe the morphologies of products. Fig. 5 shows the TEM images of $\mathrm{ZrO}_{2}$ and $\mathrm{ZrO}_{2} @ \mathrm{CeO}_{2}$ composites. It was observed that the obtained composites were irregular spheroids. Compared with the original $\mathrm{ZrO}_{2}$, the loaded $\mathrm{ZrO}_{2}$ particles exhibited a rough appearance and the size of composite particles increased by about $5 \mathrm{~nm}$, which finally confirmed that the $\mathrm{CeO}_{2}$ shells were formed on the $\mathrm{ZrO}_{2}$ surface. Based on the results of XRD, zeta potential, SEM and TEM analyses, the structure of the prepared composites could be deduced: the cubic fluorite $\mathrm{CeO}_{2}$ shells with good crystal structure were formed on the surfaces of the $\mathrm{ZrO}_{2}$ cores. Fig. 5c shows the TEM image of $\mathrm{ZrO}_{2} @ \mathrm{CeO}_{2}$ composites. Compared with Fig. 5b, the results shown that $\mathrm{CeO}_{2}$ particles did not coat $\mathrm{ZrO}_{2}$ cores compactly after calcinations. 


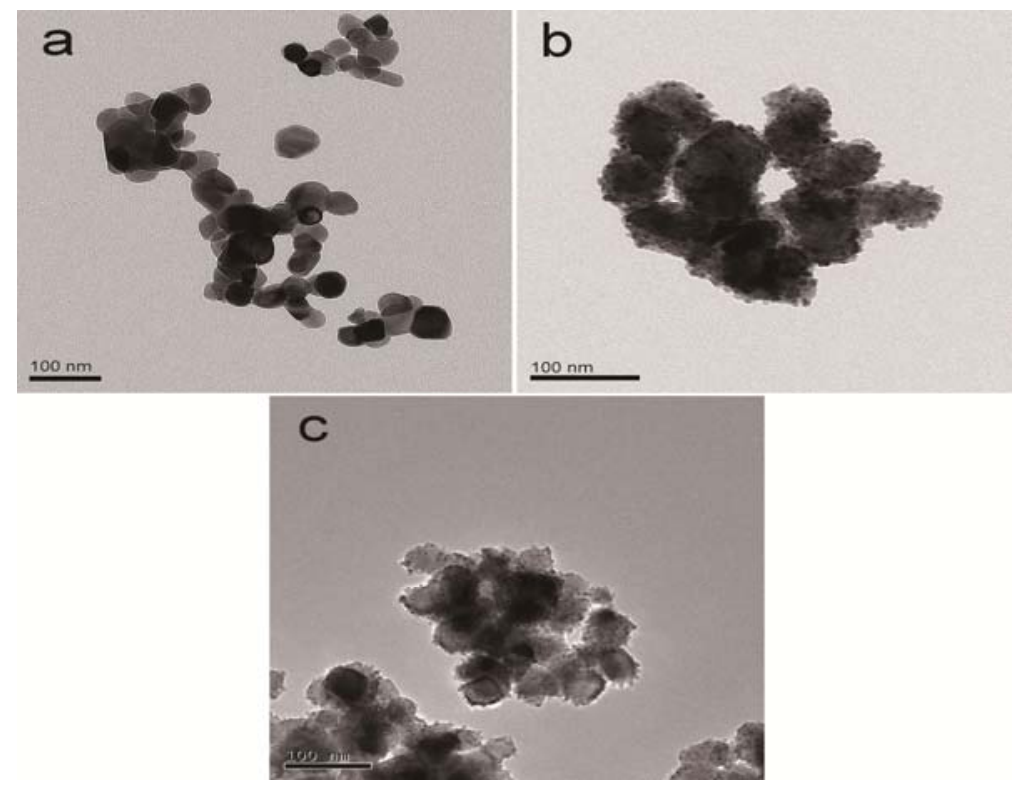

Fig. 5 TEM images of products. (a) $\mathrm{ZrO}_{2}$, (b) $\mathrm{ZrO}_{2} @ \mathrm{CeO}_{2}-\mathrm{NaOH}$ and (c) $\mathrm{ZrO}_{2} @ \mathrm{CeO}_{2}$.

\subsection{Formation mechanism.}

Based on the typical theory of electrostatic attraction, we might describe the formation mechanism of zirconia-core ceria-shell composites as follows: the first step involved the preparation of negative-charged $\mathrm{ZrO}_{2}$ particles. Secondly, with the addition of $\mathrm{Ce}\left(\mathrm{NO}_{3}\right)_{3}$ solution, $\mathrm{Ce}^{3+}$ cations were absorbed on $\mathrm{ZrO}_{2}$ particles driven by electrostatic attraction. With the $\mathrm{OH}^{-}$slowly released from the hydrolyzing of HMT, $\mathrm{Ce}^{3+}$ cations combined with $\mathrm{OH}^{-}$into $\mathrm{Ce}(\mathrm{OH})_{3}$ precipitate. Then, followed by dryness and calcination process, $\mathrm{Ce}^{3+}$ was oxidized to $\mathrm{Ce}^{4+}$ and the $\mathrm{CeO}_{2}$ shell was formed. The synthesis procedure is illustrated in Scheme 1.

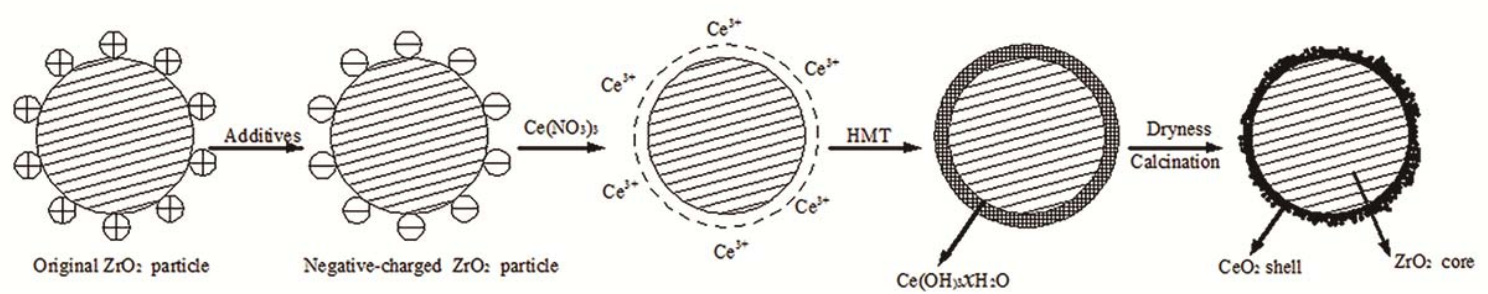

Scheme 1 Electrostatic attraction for the synthesis of $\mathrm{ZrO}_{2} @ \mathrm{CeO}_{2}$ composite particles.

However, in the coating process, heterogeneous nucleation was inevitable in the presence of $\mathrm{ZrO}_{2}$ particles. The heterogeneous nucleation surface coating process is a method based on the theory of LaMer crystallization, which takes advantage of the heterogeneous nucleation and growth of shell particles on substrate to form coating layer. As shown in Fig. 9, once the generated $\mathrm{Ce}(\mathrm{OH})_{3}$ precipitate exceeded its rate of dissolution (i.e., $C>C 1$ ), the existence of dispersed $\mathrm{ZrO}_{2}$ particles would result in the heterogeneous nucleation of $\mathrm{Ce}(\mathrm{OH})_{3}$. When the concentration of $\mathrm{Ce}(\mathrm{OH})_{3}$ in solution reached $\mathrm{C} 2$, not only would the heterogeneous nucleation and growth of $\mathrm{Ce}(\mathrm{OH})_{3}$ occur around $\mathrm{ZrO}_{2}$ particles, but also the homogeneous nucleation and growth of $\mathrm{Ce}(\mathrm{OH})_{3}$ would generate as the reaction progress. The results obtained from Fig. 2c, Fig. $4 \mathrm{c}$ and Fig. $5 \mathrm{c}$ confirmed that, in the coating process, the heterogeneous nucleation of $\mathrm{Ce}(\mathrm{OH})_{3}$ exerted a crucial influence on coating performance in the absent of electrostatic attraction between shell particles and cores. Therefore, we could suggest that in the preparation of zirconia-core ceria-shell composites by chemical precipitation method, but the electrostatic attraction, heterogeneous nucleation might also play a vital role in a certain extent. 


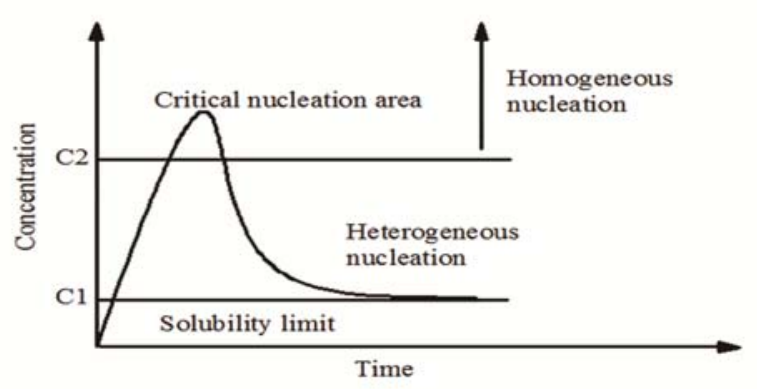

Fig. 6 The LaMer diagram of nucleation area. where $C 1$ and $C 2$ are the equilibrium concentration of solute with the bulk solid and the critical concentration as the minimum for nucleation, respectively.

\section{Conclusions}

A chemical precipitation method was firstly developed to coat tetragonal phase zirconia particles with shells of cubic fluorite phase ceria. XRD, zeta potential, SEM and TEM results confirmed that zirconia-core ceria-shell composites were successfully synthesized. Based on the experimental results, we concluded that it was an effective means to improve the coating performance by adjusting $\mathrm{pH}$ value. Moreover, we confirmed that, in the coating process, heterogeneous nucleation of precipitates played a vital role as well as the electrostatic attraction. Applications of these new materials will be published elsewhere.

\section{Acknowledgments}

This work presented herein would not be possible without the Key Scientific and Technological Research and Development Program (Grant no. 2014GZ0089 and no. 2014GZ0090-Z3) in Sichuan Province, PR China. We would like to acknowledge them for the financial support.

\section{References}

[1]. F. Caruso, M. Spasova. V, Salgueiriño-Maceira, et al. Multilayer assemblies of silica-encapsulated gold nanoparticles on decomposable colloid templates. Advanced Materials. Vol. 13 (2001) No. 14, p. 1090-1090.

[2]. U. Jeong, Y. Wang, M. Ibisate, et al. Some new developments in the synthesis, functionalization, and utilization of monodisperse colloidal spheres. Advanced Functional Materials. Vol. 15 (2005) No. 12, p. 1907-1921.

[3]. V. Salgueiriño-Maceira, M. A. Correa-Duarte, M. Spasova, et al. Composite Silica Spheres with Magnetic and Luminescent Functionalities. Advanced Functional Materials. Vol. 16 (2006) No. 10, p. 1266.

[4]. M. Tsujiguchi, T. Kobashi, Y. Utsumi, et al. Synthesis of FAU zeolite from aluminoborosilicate glass and elution behavior of glass components. Journal of the Ceramic Society of Japan. Vol. 121 (2014) No. 1421, p. 104-236.

[5]. Wenchao Duan, Wenchao Yan, Xiao Yan, et al. Synthesis of nanostructured Ni3S2 with different morphologies as negative electrode materials for lithium ion batteries. Journal of Power Sources. Vol. 293 (2015), p. 706-711.

[6]. Z. Ge, Q. Chen, K. Osada, et al. Targeted gene delivery by polyplex micelles with crowded PEG palisade and cRGD moiety for systemic treatment of pancreatic tumors. Biomaterials. Vol. 35 (2014) No. 10, 3416-3426. 
[7]. K. Minamia, T. Masuia, N. Imanakaa, et al. Redox behavior of CeO2-ZrO2-Bi2O3 and $\mathrm{CeO} 2-\mathrm{ZrO} 2-\mathrm{Y} 2 \mathrm{O} 3$ solid solutions at moderate temperatures. Journal of Alloys and Compounds. Vol. 408-412 (2006), p. 1132-1135.

[8]. A. Saadat-Monfared;M. Mohseni;M. Hashemi Tabatabaei. Polyurethane nanocomposite films containing nano-cerium oxide as UV absorber. Part 1. Static and dynamic light scattering, small angle neutron scattering and optical studies. Colloids and Surfaces. A: Physicochemical and Engineering Aspects. Vol. 408 (2012), p . 64-70.

[9]. Yang. Chen, Jinxia. Lu, Zhigang. Chen et al. Preparation, characterization and oxide CMP performance of composite polystyrene-core ceria-shell abrasives. Microelectronic Engineering. Vol. 88(2011) No. 2,p. 200-205.

[10]. S. Armini, J. D. Messemaeker, C. M. Whelan et al. Journal of the Electrochemical Society. Vol. 155(2008) No. 5, p. 653-660.

[11]. J. W. Zheng, Z. L. Wang, L. Qiao et al. Applied Surface Science. Vol. 313(2014), p. 346.

[12]. Ellawala K.C. Pradeep, Teppei Habu, Hiroko Tooriyama et al. Ultra-simple synthetic approach to the fabrication of $\mathrm{CeO} 2-\mathrm{ZrO} 2$ mixed nanoparticles into homogeneous, domain, and core-shell structures in mesoporous spherical morphologies using supercritical alcohols. The Journal of Supercritical Fluids. Vol. 97 (2015), p. 217-223.

[13]. P. W. Shen et al. Introduction of Modern Chemistry (part II ), Higher Education Press, China, 2002, p.593.

[14]. Y. Chen. The synthesis of $\mathrm{SiO} 2 / \mathrm{CeO} 2$ and $\mathrm{PS} / \mathrm{CeO} 2$, core-shell structure and its CMP performance study, D, Jangsu University, China 2012.

[15]. S. H. Lee, Z. Y. Lu, S.V. Babu et al. Chemical mechanical polishing of thermal oxide films using silica particles coated with ceria. Journal of Materials Research. Vol. 17 (2002), p. 2744-2749. 